\title{
Editorial
}

\section{Introducing Toxics}

\section{David C. Bellinger}

Boston Children's Hospital, Harvard Medical School, Harvard University, 300 Longwood Ave, Boston, MA 02115, USA; E-Mail: david.bellinger@childrens.harvard.edu; Tel.: +1-617-355-6565; Fax: +1-617-730-0618

Received: 21 March 2013; in revised form: 3 April 2013 / Accepted: 3 April 2013 /

Published: 11 April 2013

With this inaugural issue, Toxics begins its life as a peer-reviewed, open access journal focusing on all aspects of toxic chemicals. We are interested in publishing papers that present a wide range of perspectives on toxicants and naturally occurring toxins, including exposure, biomarkers, kinetics, biological effects, fate and transport, treatment, and remediation. Toxics differs from many other journals in the absence of a page or word limit on contributions, permitting authors to present their work in as much detail as they wish. Toxics will publish original research papers, conventional reviews, meta-analyses, short communications, theoretical papers, case reports, commentaries and policy perspectives, and book reviews (Book reviews will be solicited and should not be submitted without invitation). Toxins and toxicants concern individuals from a wide range of disciplines, and Toxics is interested in receiving papers that represent the full range of approaches applied to their study, including in vitro studies, studies that use experimental animal or non-animal models, studies of humans or other biological populations, and mathematical modeling. We are excited to get underway and look forward to working with authors in the scientific and medical communities and providing them with a novel venue for sharing their work.

(C) 2013 by the authors; licensee MDPI, Basel, Switzerland. This article is an open access article distributed under the terms and conditions of the Creative Commons Attribution license (http://creativecommons.org/licenses/by/3.0/). 